\title{
Circuit
}

Musiques contemporaines

\section{Créé dans Le Vivier}

\section{Gabrielle Blais-Sénéchal}

Volume 27, numéro 3, 2017

URI : https://id.erudit.org/iderudit/1042844ar

DOI : https://doi.org/10.7202/1042844ar

Aller au sommaire du numéro

\section{Éditeur(s)}

Circuit, musiques contemporaines

\section{ISSN}

1183-1693 (imprimé)

1488-9692 (numérique)

Découvrir la revue

Citer ce document

Blais-Sénéchal, G. (2017). Créé dans Le Vivier. Circuit, 27(3), 91-93.

https://doi.org/10.7202/1042844ar

Ce document est protégé par la loi sur le droit d'auteur. L'utilisation des services d'Érudit (y compris la reproduction) est assujettie à sa politique d'utilisation que vous pouvez consulter en ligne.

https://apropos.erudit.org/fr/usagers/politique-dutilisation/
Cet article est diffusé et préservé par Érudit.

Érudit est un consortium interuniversitaire sans but lucratif composé de l’Université de Montréal, l'Université Laval et l'Université du Québec à Montréal. Il a pour mission la promotion et la valorisation de la recherche. https://www.erudit.org/fr/ 


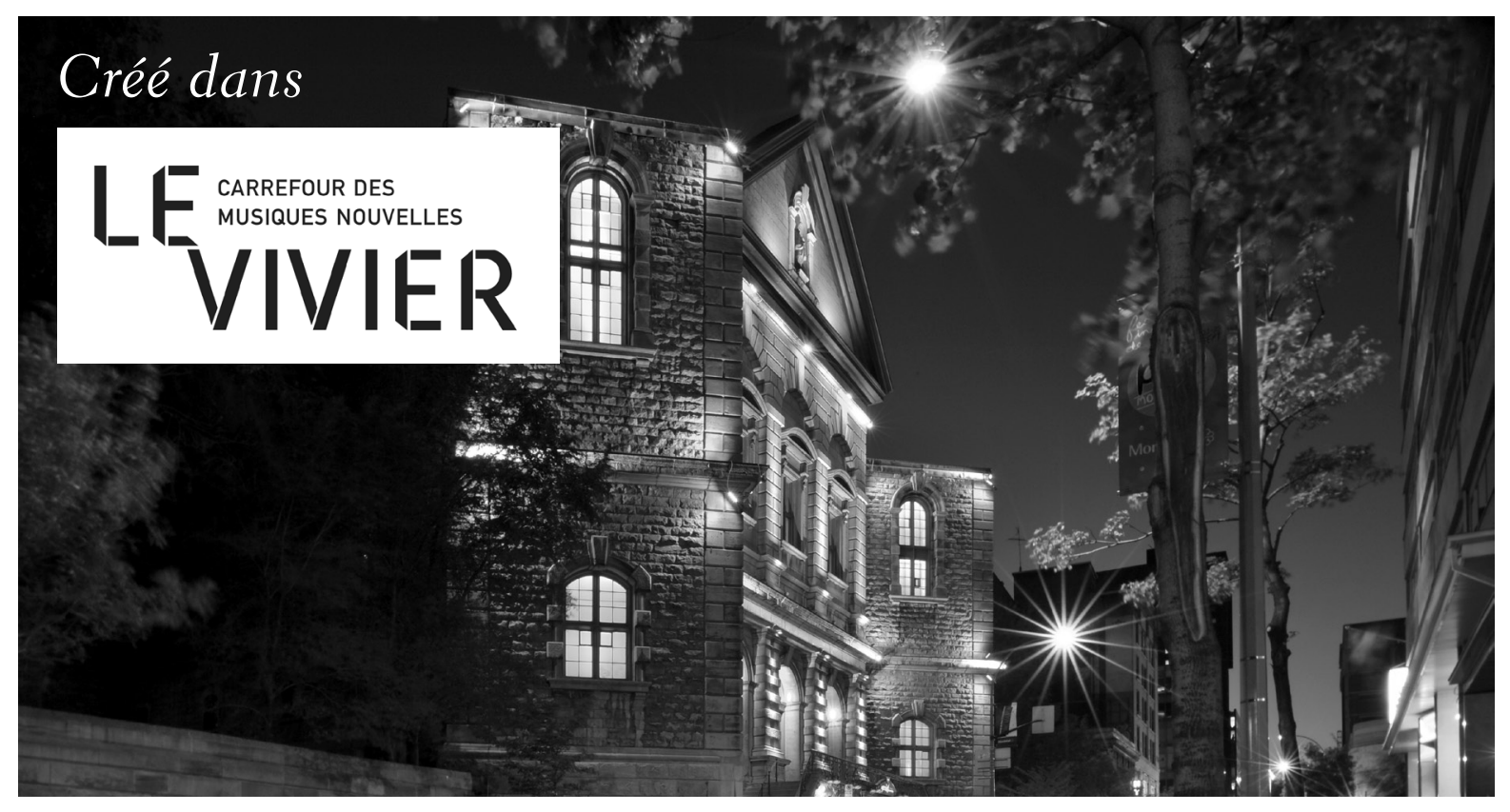

Photo : Le Gesù.

Gabrielle Blais-Sénéchal

Installé dans l'enceinte du Gesù - Centre de créativité depuis janvier 2015 -, Le Vivier, diffuseur spécialisé et regroupement de 45 membres, dont 34 ensembles et organismes dédiés aux musiques de création, réside dans ce lieu mythique de la culture afin d'implanter à Montréal un véritable carrefour des musiques nouvelles. Sa principale mission est de favoriser le développement des musiques nouvelles et d'offrir à tous, par la diffusion d'œuvres de qualité, une porte ouverte sur la culture. La revue Circuit veut mettre en valeur les créateurs et interprètes en présentant une liste des œuvres jouées en création dans le cadre de la série de concerts du Groupe Le Vivier¹.

\section{- Saison artistique 2016-2017 -}

Sixtrum • Sixtrum - 10 ans de création

Tim Brady $\bullet$ Fast

28 septembre 2016

Pierre Michaud $\bullet$ Enso

Alain Perron • Débacle

Sixtrum: Noam Bierstone, João Catalão, Julien Grégoire, Philip Hornsey, Amphithéâtre - Le Gesù

Kristie Ibrahim, Fabrice Marandola (percussions) 
29 septembre et $1^{\text {er }}$ octobre 2016 Espace Aline-Letendre Le Gesù

18 octobre 2016

Amphithéâtre - Le Gesù

10 novembre 2016

Amphithéâtre - Le Gesù

7 janvier 2017

Amphithéâtre - Le Gesù

22 janvier 2017

Amphithéâtre et Espace AlineLetendre - Le Gesù
Espaces sonores illimités et Magnitude6 • Traces dans l'espace

Julien-Robert $\bullet$ L'entropie

ANDRÉ HAMEL • Traces de vie

Alain Lalonde $\bullet$ Traces de violences, pistes d'amour

Alain Dauphinais $\bullet$ SN 1314

Magnitude6: Thierry Champs (trompette), Frédéric Demers (trompette), Laurence Latreille-Gagné (cor), Samuel Lalande-Markon (tuba), Simon Jolicoeur-Côté (trombone), Frédéric Lapointe (percussions)

Réseaux des arts médiatiques $\bullet$ Akousma 13 - maximalus échantillonné

Paul Dolden • Music of Another Present Era

Paul Dolden (diffusion)

Quasar • In Vivo 8: jouer avec le feu

PedRo Rebelo $\bullet$ In a Line

JEAN-Marc BOUCHARD $\bullet$ Clair / obscur

Quasar: Marie-Chantal Leclair (saxophone soprano), Mathieu Leclair (saxophone alto), André Leroux (saxophone ténor), Jean-Marc Bouchard (saxophone baryton); Pedro Rebelo (piano), Franziska Schroeder (saxophone)

Innovations en concert • Maxime McKinley: brèches opéradiques (d'après Philippe Beck)

Maxime McKinley / Philippe BecK • Musicole (brèches opéradiques d'après Philippe Beck)

Daniel Añez (piano), Marie-Annick Béliveau (mezzo-soprano), Noam Bierstone (percussions), Elinor Frey (violoncelle), Vincent Lauzer (flûtes à bec), Mélisande McNabney (clavecin), Brigitte Poulin (piano)

Groupe Le Vivier • Journée Portes Ouvertes 2017 - $3^{e}$ édition

Jean-Paul Dessy • Amos, Isaïe, Semper gaudete

Jean-Paul Dessy (violoncelle)

Louis Dufort $\bullet$ I Am, You Are, We Are Plastic

Louis Dufort (diffusion), Claire Marchand (flûte) 
DAME et Productions SuperMusique (PSM) • DAME : archive / mémoire Sсотт ThOMSON • Archive / mémoire

Ensemble SuperMusique: Michel F. Côté (percussions, voix), Jean Derome (saxophone alto, flûte, voix), Bernard Falaise (guitare électrique), Lori Freedman (clarinettes), Émilie Girard-Charest (violoncelle), Joane Hétu (saxophone alto, voix), Diane Labrosse (échantillonneur), Philippe Lauzier (clarinette basse, saxophone soprano), Geneviève Liboiron (violon), PierreYves Martel (contrebasse), Craig Pedersen (trompette), Jean René (alto), Danielle Palardy Roger (percussions, voix), Alexandre St-Onge (basse électrique), Pierre Tanguay (batterie), Martin Tétreault (tourne-disques), Scott Thombson (signaux)

Bradyworks • Tournée canadienne - Le guide du bonheur

Emily HaLl $\bullet$ The Happiness Handbook

SCOTt EdWARd Godin $\bullet$ Martlandia

Gordon FitZELL • Bomb Crater Garden

MaXime McKinley $\bullet$ Reflets de Francesca Woodman

Jordan Nobles $\bullet$ Deep Field

Tim BRADY $\bullet$ Equal but Opposite Reaction

Instruments of Happiness: Tim Brady, Jonathan Barriault, Simon Duchesneau, Marc-Olivier Lamontagne (guitares électriques)

Projections libérantes $\bullet$ Musique d'art pour cor, trombone, tuba et électronique Simon Martin • Musique d'art pour cor, trombone, tuba et électronique Zinc \& Copper : Elena Margarita Kakaliagou (cor), Hilary Jeffery (trombone), Robin Hayward (tuba microtonal)

\footnotetext{
1. Notez que l'on répertorie ici seulement les œuvres créées lors des concerts inclus dans la saison artistique officiellement présentée par Le Vivier, mais que plusieurs organismes membres présentent aussi d'autres concerts au Gesù au cours de l'année où adviennent également de nombreuses créations.
}

16 février 2017

Amphithéâtre - Le Gesù

9 avril 2017

Amphithéâtre - Le Gesù

31 mai 2017

Espace Aline-Letendre Le Gesù 